\title{
Adolescent Scoliosis Screening in Nara City Schools: A 23-Year Retrospective Cross-Sectional Study
}

\author{
Satoshi Yamamoto ${ }^{1}$, Hideki Shigematsu ${ }^{2}$, Fumihiko Kadono ${ }^{3}$, Yukihiro Tanaka ${ }^{4}$, \\ Masataka Tatematsu ${ }^{5}$, Akinori Okuda ${ }^{2}$, Eiichiro Iwata ${ }^{2}$, Munehisa Koizumi ${ }^{2}$, Yasuhito Tanaka ${ }^{2}$ \\ ${ }^{1}$ Department of Orthopedics and Surgery, Nara City Hospital, Nara, Japan \\ ${ }^{2}$ Department of Orthopedics and Surgery, Nara Medical University, Kashihara, Japan \\ ${ }^{3}$ Department of Orthopedics and Surgery, Kadono Clinic, Nara, Japan \\ ${ }^{4}$ Department of Orthopedics and Surgery, Tanaka Clinic, Nara, Japan \\ ${ }^{5}$ Department of Orthopedics and Surgery, Hanna Central Hospital, Nara, Japan
}

Study Design: Retrospective cross-sectional study.

Purpose: To determine the prevalence of idiopathic scoliosis, define the distribution of the curve magnitude, evaluate the accuracy of Moiré topography as a screening tool, and investigate the cost-effectiveness of our screening system.

Overview of Literature: Early detection of idiopathic scoliosis provides the opportunity for conservative treatment before the deformity is noticeable. We believe that scoliosis screening in schools is useful for detection; however, screening programs are controversial owing to over referral of students who do not require further testing or follow-up. In Japan, school scoliosis screening programs are mandated by law with individual policies determined by local educational committees. We selected Moiré topography as the scoliosis screening tool for schools in Nara City.

Methods: We selected Moiré topography as the scoliosis screening tool for schools in Nara City. We screened boys and girls aged 11-14 years and reviewed the school scoliosis screening results from 1990 to 2012.

Results: A total of 195,149 children aged 11-14 years were screened. The prevalence of scoliosis (defined as $210^{\circ}$ curvature) was $0.057 \%, 0.010 \%$, and $0.059 \%$ in fifth, sixth, and seventh grade boys and $0.337 \%, 0.369 \%$, and $0.727 \%$ in fifth, sixth, and seventh grade girls, respectively. The false-positive rate of our Moiré topography was $66.7 \%$. The minimum cost incurred for scoliosis detection in one student was 2,000 USD.

Conclusions: The overall prevalence of scoliosis was low in the students of Nara City schools. Over 23 years, the prevalence of scoliosis in girls increased compared to that in the first decade of the study.

Keywords: Scoliosis; Mass screening; Prevalence; Moiré topography; Costs and cost analysis

\section{Introduction}

Adolescent idiopathic scoliosis is defined as a lateral curvature of the spine $\geq 10^{\circ}$. Although the rate of change is unpredictable, rapid progression of the curvature can occur. Severe curve deformity is a cosmetic concern, and

Received Oct 25, 2014; Revised Dec 28, 2014; Accepted Dec 28, 2014

Corresponding author: Hideki Shigematsu

Department of Orthopaedics and Surgery, Nara Medical University, 840 Shijocho, Kashihara 634-0813, Japan

Tel: +81-744-22-3051, Fax: +81-744-29-6443, E-mail: shideki714@gmail.com 
more importantly, it is associated with an increased risk of mortality and morbidity [1]. It is important to detect scoliosis in its early stages and begin conservative treatment with bracing early in the disease course to prevent progression to severe scoliosis, which requires invasive treatment [2].

While there is agreement that the early detection of scoliosis is important, the need for a screening program in all schools has been debated [3,4]. Currently, insufficient evidence for both recommending and rejecting routine screening exists [5].

The main concerns about routine screening are unnecessary referrals and excessive costs owing to a high falsepositive rate $[3,6]$. However, we believe that it is a powerful tool to detect scoliosis at an early stage in children.

Several screening methods exist. The most widely used is the forward bending test, which has high falsepositive and false-negative rates [4,7]. Moiré topography is a biostereometric screening technique that projects contour lines, or Moiré fringes, on a subject's back $[8,9]$. This method is more sensitive than conventional clinical screening including the forward bending test [10].

Routine school scoliosis screening was initiated as part of the national school health screening program in Nara City in 1978. Moiré topography was adopted as the preferred screening test in 1989. Currently, we routinely screen the fifth and seventh grade students.

The objectives of our study were to (1) determine the prevalence of adolescent idiopathic scoliosis over 23 years (1990-2012) and compare the prevalence between the first and last decades of that time period; (2) evaluate the curve magnitude and distribution; (3) evaluate the accuracy of Moiré topography as a screening tool by determining its false-positive rate; and (4) investigate the cost to detect scoliosis with our screening system.

\section{Materials and Methods}

The authors obtained approval for this study design and the publication of this manuscript from the Nara City Medical Association.

\section{Subjects}

This retrospective cross-sectional study included 195,149 public school children who were screened for scoliosis in Nara City from 1990 to 2012. Students of two school grades (fifth and seventh grades) were routinely screened. Moreover, we screened sixth grade students between 1993 and 2002. The ages of the fifth, sixth, and seventh grade students were 11-12 years, 12-13 years, and 13-14 years, respectively.

\section{School scoliosis screening program in Nara City}

The initial screening was performed using Moiré topography by 1 nurse and 1 radiology technician in all the schools. We included children previously diagnosed with or currently being managed for scoliosis. Each child was told to stand erect in a relaxed position for approximately 1 minute. A Moiré photograph was taken; the number of fringes on each half of the back were compared and determined to be symmetric or asymmetric. One spine specialist reviewed all of the photographs to identify abnormal Moiré patterns (asymmetry indicating a rotational component) or abnormal clinical signs such as an uneven shoulder height, pelvic tilt, or waistline differences (abnormalities indicating lateral deviation). Students with abnormal findings were referred for radiography. Because it was not compulsory, radiography was not performed for all students. Those found to have a Cobb angle $\geq 20^{\circ}$ were referred to a spine specialist for additional intervention such as a brace treatment.

\section{Data collection}

In our cohort, the demographic information, school grade, date, and results of tests were obtained at each visit, and the Cobb angle measurements were obtained from the Nara City Medical Association.

\section{Statistical analysis}

Prevalence rates were calculated at predefined Cobb angles of $10^{\circ}-19^{\circ}$ and $\geq 20^{\circ}$. A Cobb angle of $\geq 10^{\circ}$, as defined by the Scoliosis Research Society, was considered positive for scoliosis; an angle $\geq 20^{\circ}$ was the threshold for evaluation for brace treatment.

1) Prevalence of scoliosis

Using a chi-square test, we compared the prevalence of scoliosis between the first decade (1990-1999) and the last decade (2003-2012) to determine changes in prevalence over time. 
Table 1. The prevalence of scoliosis in each grade group from 1990 to 2012

\begin{tabular}{|c|c|c|c|c|c|c|c|c|}
\hline \multirow{2}{*}{ Age/Sex } & \multirow{2}{*}{$\begin{array}{l}\text { No. of } \\
\text { students } \\
\text { (A) }\end{array}$} & $\begin{array}{c}\text { Moiré (+) } \\
\text { but declined }\end{array}$ & \multicolumn{2}{|c|}{$10^{\circ}<\mathrm{Cobb}<19^{\circ}$} & \multicolumn{2}{|c|}{$\mathrm{Cobb} \geq 20^{\circ}$} & \multicolumn{2}{|r|}{ All } \\
\hline & & $\begin{array}{l}\text { No. of } \\
\text { students }\end{array}$ & $\begin{array}{l}\text { No. of } \\
\text { students } \\
\text { (B) }\end{array}$ & $\begin{array}{c}\text { Prevalence } \\
(B / A \times 100)\end{array}$ & $\begin{array}{l}\text { No. of } \\
\text { students } \\
\text { (C) }\end{array}$ & $\begin{array}{c}\text { Prevalence } \\
(\mathrm{C} / \mathrm{A} \times 100)\end{array}$ & $\begin{array}{l}\text { No. of } \\
\text { students } \\
(B+C)\end{array}$ & $\begin{array}{c}\text { Prevalence } \\
{[(B+C) / A \times 100]}\end{array}$ \\
\hline \multicolumn{9}{|l|}{ Fifth grade } \\
\hline Boy & 41,854 & 17 & 23 & 0.055 & 1 & 0.002 & 24 & 0.057 \\
\hline Girl & 39,489 & 53 & 107 & 0.271 & 26 & 0.066 & 133 & 0.337 \\
\hline \multicolumn{9}{|l|}{ Sixth grade } \\
\hline Boy & 19,329 & 7 & 2 & 0.010 & 0 & 0.000 & 2 & 0.010 \\
\hline Girl & 18,413 & 54 & 49 & 0.266 & 19 & 0.103 & 68 & 0.369 \\
\hline \multicolumn{9}{|c|}{ Seventh grade } \\
\hline Boy & 38,920 & 25 & 19 & 0.049 & 4 & 0.010 & 23 & 0.059 \\
\hline Girl & 37,144 & 103 & 177 & 0.477 & 93 & 0.250 & 270 & 0.727 \\
\hline Total & 195,149 & 259 & 377 & 0.193 & 143 & 0.073 & 520 & 0.266 \\
\hline
\end{tabular}

\section{2) Accuracy of Moiré topography}

We calculated the false-positive rate to evaluate the accuracy of the Moiré topography test using the following formula:

$$
\frac{\text { No. of students Cobb angle }<10^{\circ}}{\text { No. of students which radiographs screened }} \times 100(\%)
$$

Using a chi-square test, we compared the false-positive rate from the first decade (1990-1999) with that from the last decade (2003-2012) to determine changes in the false-positive rate over time.

Some students declined radiography although their Moiré topography was positive. We excluded these student data.

\section{3) Cost of scoliosis screening}

We investigated the cost of the initial and second screening including diagnostic costs and staff salaries. Finally, we calculated the cost to identify one scoliosis student with a lateral curvature of $\geq 10^{\circ}$.

\section{Results}

\section{Prevalence of scoliosis}

The overall prevalence rates are shown in Table 1 . The prevalence rates from 1990 to 1999 are shown in Table 2, and those from 2003 to 2012 are shown in Table 3. Of the students with positive Moiré topography, 259 declined to undergo radiography and were excluded from the study.

\section{1) Overall prevalence of scoliosis}

The prevalence rate of scoliosis in the fifth grade girls was similar to that in the sixth grade girls $(0.337$ and 0.369 , respectively). The prevalence rate of scoliosis in the seventh grade girls was 0.727 , which was significantly higher than that in both the fifth $(p<0.01)$ and sixth $(p<0.01)$ grade girls. The prevalence rate of scoliosis in boys was low, and the prevalence rate in the sixth grade boys was 0.01 , which was significantly lower than that in both the fifth ( $p=0.01)$ and seventh $(p=0.01)$ grade boys (Table 1$)$.

\section{2) Cobb angle $\geq 20^{\circ}$}

The prevalence rates in girls gradually increased from the fifth to the seventh grade. Meanwhile, for boys, the prevalence rates did not change among the three groups (Table 1).

3) Comparison of prevalence in the first and last decade of the study

The prevalence of scoliosis from 1990 to 1999 is shown in Table 2 and from 2003 to 2012 in Table 3. The prevalence rate was significantly different between the first and last 
Table 2. The prevalence of scoliosis in each grade group from 1990 to 1999

\begin{tabular}{|c|c|c|c|c|c|c|c|c|}
\hline \multirow{2}{*}{ Age/Sex } & \multirow{2}{*}{$\begin{array}{l}\text { No. of } \\
\text { students } \\
\text { (A) }\end{array}$} & $\begin{array}{c}\text { Moiré (+) } \\
\text { but declined }\end{array}$ & $10^{\circ}<$ Cob & angle $<19^{\circ}$ & \multicolumn{2}{|c|}{ Cobb angle $\geq 20^{\circ}$} & \multicolumn{2}{|r|}{ All } \\
\hline & & $\begin{array}{l}\text { No. of } \\
\text { students }\end{array}$ & $\begin{array}{l}\text { No. of } \\
\text { students } \\
\text { (B) }\end{array}$ & $\begin{array}{c}\text { Prevalence } \\
(\mathrm{B} / \mathrm{A} \times 100)\end{array}$ & $\begin{array}{l}\text { No. of } \\
\text { students } \\
\text { (C) }\end{array}$ & $\begin{array}{l}\text { Prevalence } \\
(\mathrm{C} / \mathrm{A} \times 100)\end{array}$ & $\begin{array}{c}\text { No. of } \\
\text { students } \\
(B+C)\end{array}$ & $\begin{array}{c}\text { Prevalence } \\
{[(B+C) / A \times 100]}\end{array}$ \\
\hline
\end{tabular}

Fifth grade

\begin{tabular}{crrrrrrrrr} 
Boy & 20,579 & 8 & 14 & 0.068 & 0 & 0.000 & 14 & 0.068 \\
\hline Girl & 19,536 & 21 & 44 & 0.225 & 9 & 0.046 & 53 & 0.271 \\
\hline Seventh grade & & & & & & & & \\
\hline Boy & 19,887 & 8 & 10 & 0.050 & 2 & 0.010 & 12 & 0.060 \\
Girl & 19,167 & 42 & 96 & 0.501 & 30 & 0.157 & 126 & 0.657 \\
\hline Total & 79,169 & 79 & 164 & 0.207 & 41 & 0.052 & 205 & 0.259 \\
\hline
\end{tabular}

Table 3. The prevalence of scoliosis in each grade group from 2003 to 2012

\begin{tabular}{|c|c|c|c|c|c|c|c|c|}
\hline \multirow{2}{*}{ Age/Sex } & \multirow{2}{*}{$\begin{array}{l}\text { No. of } \\
\text { students } \\
\text { (A) }\end{array}$} & $\begin{array}{l}\text { Moiré (+) } \\
\text { but declined } \\
\text { radioaraphy }\end{array}$ & \multicolumn{2}{|c|}{$10^{\circ}<$ Cobb angle $<19^{\circ}$} & \multicolumn{2}{|c|}{ Cobb angle $\geq 20^{\circ}$} & \multicolumn{2}{|r|}{ All } \\
\hline & & $\begin{array}{c}\text { No. of } \\
\text { students }\end{array}$ & $\begin{array}{l}\text { No. of } \\
\text { students } \\
\text { (B) }\end{array}$ & $\begin{array}{c}\text { Prevalence } \\
(\mathrm{B} / \mathrm{A} \times 100)\end{array}$ & $\begin{array}{l}\text { No. of } \\
\text { students } \\
\text { (C) }\end{array}$ & $\begin{array}{l}\text { Prevalence } \\
(\mathrm{C} / \mathrm{A} \times 100)\end{array}$ & $\begin{array}{l}\text { No. of } \\
\text { students } \\
(B+C)\end{array}$ & $\begin{array}{c}\text { Prevalence } \\
{[(\mathrm{B}+\mathrm{C}) / \mathrm{A} \times 100]}\end{array}$ \\
\hline
\end{tabular}

Fifth grade

\begin{tabular}{cccccccccc} 
Boy & 16,344 & 7 & 8 & 0.049 & 1 & 0.006 & 9 & 0.055 \\
\hline Girl & 15,281 & 30 & 59 & $0.386^{\text {a) }}$ & 14 & 0.092 & 73 & $0.478^{\text {b) }}$ \\
\hline Seventh grade & & & & & & & & \\
\hline Boy & 14,365 & 16 & 8 & 0.056 & 2 & 0.014 & 10 & 0.070 \\
\hline Girl & 13,622 & 47 & 69 & 0.507 & 53 & $0.389^{\text {c) }}$ & 122 & $0.896^{\text {d) }}$ \\
\hline Total & 59,612 & 100 & 144 & 0.242 & 70 & 0.117 & 214 & 0.359 \\
\hline
\end{tabular}

Compared with the prevalence between 1990-1999 and 2003-2012.

Chi-square test: ${ }^{\text {a) }} p<0.01,{ }^{\text {b) }} p<0.01,{ }^{\text {c) }} p<0.01,{ }^{d)} p=0.01$.

decade for girls in the fifth grade with a Cobb angle $>10^{\circ}$ but $<19^{\circ}(0.225 \%$ vs. $0.386 \%, p<0.01)$ and for girls in the seventh grade with a Cobb angle $>20^{\circ}(0.157 \%$ vs. $0.389 \%)$. A statistically significant increase was also found in the overall prevalence during the 10 years.

4) Curve magnitude distribution

The distribution of curve magnitudes for boys and girls is shown in Fig. 1.

The prevalence of a Cobb angle $\geq 20^{\circ}$ gradually increased with age in both boys and girls. The prevalence was similar among boys in the fifth, sixth, and seventh grades. The difference in the percentage of children with a Cobb angle $\geq 20^{\circ}$ was statistically significant only between girls in the fifth and seventh grades $(19.6 \%$ vs. $34.4 \%$, $p=0.002$ ).

\section{Accuracy of Moiré topography}

From 1990 to 2012, 1,820 children had a positive Moiré topography test (Table 4 ). Of those, 259 children (49 boys, 210 girls) declined to undergo radiography and were ex- 


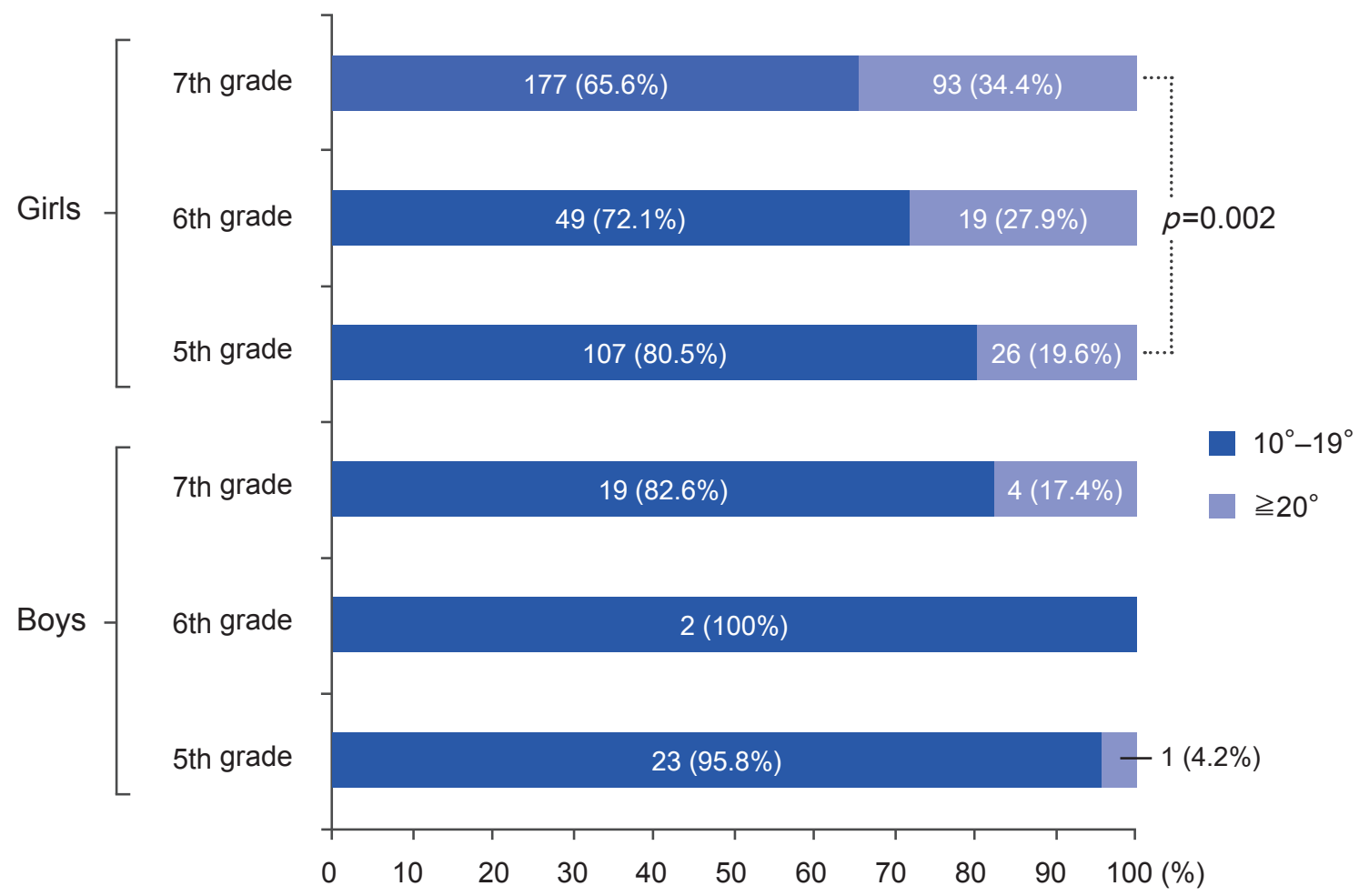

Fig. 1. Distribution of curve magnitudes for boys and girls. Scoliosis is defined as a Cobb angle $\geq 10^{\circ}$. The need for additional intervention such as brace treatment was indicated in cases with a Cobb angle $\geq 20^{\circ}$. A statistically significant difference in the prevalence of scoliosis between girls of fifth and seventh grade occurred.

Table 4. Overall false-positive ratios in patients who showed positive results on Moiré topography from 1990 to 2012

\begin{tabular}{|c|c|c|c|c|c|}
\hline Age/Sex & $\begin{array}{l}\text { Moiré (+) } \\
\text { (A) }\end{array}$ & $\begin{array}{l}\text { Moiré (+) but declined } \\
\text { radiography (B) }\end{array}$ & $\begin{array}{l}\text { No. of radiographs } \\
\text { screened (A-B) }\end{array}$ & $\begin{array}{c}\text { Cobb angle }<10^{\circ} \\
\text { (C) }\end{array}$ & $\begin{array}{l}\text { False-positive rate (\%) } \\
{[C /(A-B) \times 100(\%)]}\end{array}$ \\
\hline \multicolumn{6}{|l|}{ Fifth grade } \\
\hline Boy & 156 & 17 & 139 & 115 & 82.7 \\
\hline Girl & 526 & 53 & 473 & 340 & 71.9 \\
\hline \multicolumn{6}{|l|}{ Sixth grade } \\
\hline Boy & 37 & 7 & 30 & 28 & 93.3 \\
\hline Girls & 211 & 54 & 157 & 89 & 56.7 \\
\hline \multicolumn{6}{|c|}{ Seventh grade } \\
\hline Boy & 151 & 25 & 126 & 103 & 81.8 \\
\hline Girl & 739 & 103 & 636 & 366 & 57.6 \\
\hline Total & 1,820 & 259 & 1,561 & 1,041 & 66.7 \\
\hline
\end{tabular}

Values are presented as no. of students.

cluded from the study. Consequently, radiographs from 1,561 students with a positive Moiré topography test were analyzed. When the radiographs were interpreted, a Cobb angle $\geq 10^{\circ}$ was seen in only 520 students (predictive value: $33.3 \%$ ), thus leaving 1,041 children with a positive screening test but a negative result on radiographs. Of these children, 795 were girls, and 246 were boys; thus, the Moiré test had a false-positive rate of $66.7 \%$ (Table 4 ).

We compared the false-positive rate between 1990-1999 and 2003-2012 and between genders. A statistically sig- 
Table 5. The false-positive ratios in Moiré topography from 1990 to 1999

\begin{tabular}{|c|c|c|c|c|c|}
\hline Age/Sex & $\begin{array}{l}\text { Moiré (+) } \\
\text { (A) }\end{array}$ & $\begin{array}{l}\text { Moiré }(+) \text { but declined } \\
\text { radiography }(B)\end{array}$ & $\begin{array}{l}\text { No. of radiographs } \\
\text { screened (A-B) }\end{array}$ & $\begin{array}{l}\text { Cobb angle }<10^{\circ} \\
\text { (C) }\end{array}$ & $\begin{array}{l}\text { False-positive rate (\%) } \\
{[\mathrm{C} /(\mathrm{A}-\mathrm{B}) \times 100(\%)]}\end{array}$ \\
\hline \multicolumn{6}{|l|}{ Fifth grade } \\
\hline Boy & 90 & 8 & 82 & 68 & 82.9 \\
\hline Girl & 236 & 21 & 215 & 162 & 75.3 \\
\hline \multicolumn{6}{|c|}{ Seventh grade } \\
\hline Boy & 83 & 8 & 75 & 63 & 84.0 \\
\hline Girl & 372 & 42 & 330 & 204 & 61.8 \\
\hline Total & 781 & 79 & 702 & 497 & 70.8 \\
\hline
\end{tabular}

Values are presented as no. of students.

Table 6. The false-positive ratios in Moiré topography from 2003 to 2012

\begin{tabular}{|c|c|c|c|c|c|}
\hline Age/Sex & $\begin{array}{l}\text { Moiré (+) } \\
\text { (A) }\end{array}$ & $\begin{array}{l}\text { Moiré }(+) \text { but declined } \\
\text { radiography }(B)\end{array}$ & $\begin{array}{l}\text { No. of radiographs } \\
\text { screened }(A-B)\end{array}$ & $\begin{array}{c}\text { Cobb angle }<10^{\circ} \\
\text { (C) }\end{array}$ & $\begin{array}{l}\text { False-positive rate (\%) } \\
\qquad[\mathrm{C} /(\mathrm{A}-\mathrm{B}) \times 100(\%)]\end{array}$ \\
\hline \multicolumn{6}{|l|}{ Fifth grade } \\
\hline Boy & 58 & 7 & 51 & 42 & 82.4 \\
\hline Girl & 262 & 30 & 232 & 159 & 68.5 \\
\hline \multicolumn{6}{|c|}{ Seventh grade } \\
\hline Boy & 62 & 16 & 46 & 36 & 78.3 \\
\hline Girl & 307 & 47 & 260 & 138 & $53.1^{\text {a) }}$ \\
\hline Total & 689 & 100 & 589 & 375 & 63.7 \\
\hline
\end{tabular}

Values are presented as no. of students.

There was statistically significant difference between 1990-1999 and 2003-2012 regarding false-positive rate of seventh grade girls only. ${ }^{\text {a) }} p=0.007$.

nificant decrease in the false-positive rate was found between the first and last decades of the study in the seventh grade girls (61.8 vs. $53.1, p=0.007$ ). No other significant change was found (Tables 5,6 ).

\section{Cost of scoliosis screening}

We screened 195,149 students with Moiré topography. The cost of Moiré topography for each child was 5 USD. Furthermore, we used radiography as the second screening tool for diagnosing scoliosis in 1,561 students. Its cost was 40 USD for each child. In all, 520 students with Cobb angle $\geq 10^{\circ}$ were identified. Of those, 143 students had a Cobb angle $\geq 20^{\circ}$. Overall, an amount of $1,996.5$ USD was required to identify one scoliosis student and an amount of 7,260 USD was required to identify one student with a Cobb angle $\geq 20^{\circ}$.

\section{Discussion}

\section{Prevalence of scoliosis}

A review of multiple studies in the literature revealed that the prevalence of idiopathic scoliosis was $0.04 \%-0.66 \%$ in boys and $0.4 \%$ to $2.22 \%$ in girls [7,11-13]. Boys generally have a lower prevalence than girls. Although lack of standardization and consistency in the cohort age group, diagnostic criteria, and screening methods makes comparing studies difficult, we found the prevalence in Nara City to be consistent with that reported in the literature [7,11-13] for boys but slightly lower in girls (Table 1).

However, the prevalence in the current decade of our study was higher than that in the first decade, especially for girls in the fifth and seventh grades. We were unable to identify the exact reason for this difference. Progression of the curve magnitude in scoliosis is related to growth 
velocity $[14,15]$. In girls, menarche is strongly associated with growth velocity [16]. Orito et al. [17] reported that the mean age of menarche in Japanese girls was $12.0 \pm 1.2$ years. We do not have data regarding growth velocity and height change for the participants in our study; however, the girls in our study were at the mean age for menarche and, therefore, had an increased growth velocity. Although the increased prevalence of scoliosis in girls over the last 23 years seen in our study may be related to a higher growth velocity in girls in the last decade compared with that in the first decade, we do not have data to support this hypothesis; this difference requires further research.

\section{Accuracy of Moiré topography}

Moire topography was the only test that was used in this study for school screening. Based on our results, the screening test's false-positive rate ranged from $56.7 \%$ to 93.3\%, which was high in both sexes but was higher in boys. This high false-positive rate leads to over referral and unnecessary additional medical costs. No significant improvement in the false-positive rate was found between the first and current decades except in seventh grade girls. Because a single spine specialist performed all of the screening tests, the fact that the false-positive rate did not change indicates that it did not improve with experience. Moreover, the examiner was undoubtedly concerned about the test missing children with scoliosis. This concern could account for high false-positive rates.

An assessment of the correlation between the prevalence of scoliosis and false-positive rate revealed a significant negative relationship. In other words, the falsepositive rate increased even as the prevalence of scoliosis decreased (Fig. 2) (by Pearson's correlation coefficient analysis, $r=-0.52, p<0.001)$. To reduce costs and over referrals, more research is necessary to determine and incorporate ways of reducing the high false-positive rate observed in our screening program. Fong et al. [18] suggested that a combined examination (e.g., the angle of trunk rotation combined with Moiré topography or lowdose radiography) improved the accuracy of screening results. Because the angle of trunk rotation can be used to screen many students quickly and inexpensively, we think that this technique should be used with Moiré topography in any future screenings.

\section{Cost of our scoliosis screening}

The cost of our scoliosis screening was much lower than that of the invasive treatment required for advanced scoliosis. All screening costs were covered by our municipal government. As shown in our results, an amount of 1,996.5 USD was required for our school screening system to identify one scoliosis student, and an amount of 7,260 USD was required to identify one student with Cobb angle $\geq 20^{\circ}$. The cost for surgical intervention involving fusion of more than 5 vertebrae in Japan is at least 13,900 USD, which is strictly the surgery cost and does not include costs incurred during the hospital stay. With regard to the cost for identifying one student with Cobb angle $\geq 20^{\circ}$, our scoliosis screening system did not exceed the surgical costs. Yawn and Yawn [19] reported the cost for identifying one student with a curve of $20^{\circ}$ or more by age 19 in Minnesota, USA, was 3,386 USD. In comparison with the cost reported by them, our scoliosis screening system required over twice the amount, which may be attributable to the high false-positive rate of the Moiré topography test.

In this study, we only focused on the cost incurred to identify one scoliosis student. We did not attempt to assess the benefits of scoliosis screening to allow for a cost-benefit analysis. Such an analysis would require the determination of short- and long-term benefits of early diagnosis and treatment of adolescent idiopathic scoliosis

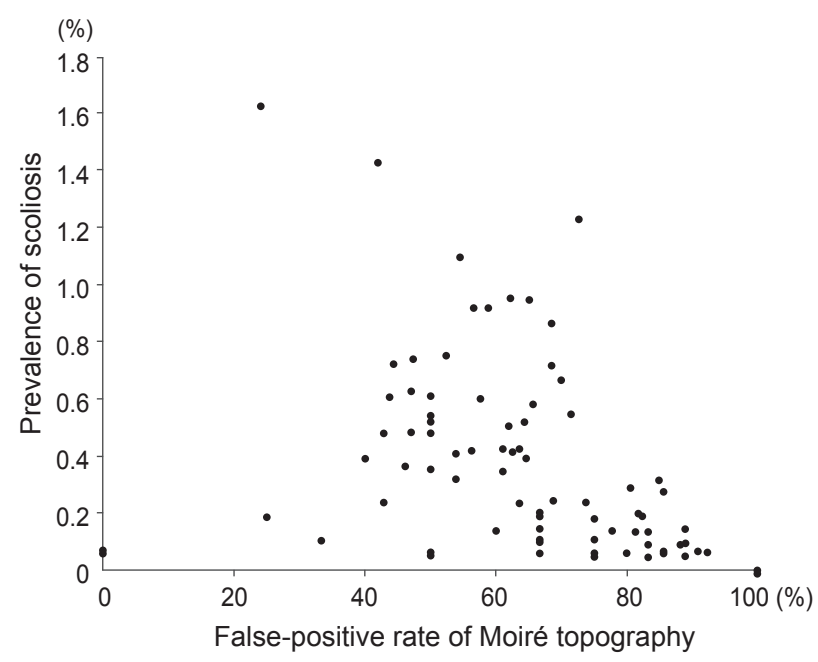

Fig. 2. Prevalence of scoliosis and false-positive rates. A statistically negative correlation was found between the prevalence of scoliosis and the false-positive rate of Moiré topography in boys and girls $(r=-0.52, p<0.001)$. 
such as a potential reduction in the number and complexity of spinal surgeries for scoliosis. One of the several limitations of our study was that our scoliosis screening system could not follow scoliosis students until skeletal maturity was achieved. Therefore, we did not have inclusive data from initial screening through skeletal maturity. The aim of school screening is early diagnosis so that conservative treatment with bracing can be used and invasive intervention can be avoided, and the effectiveness of a screening program is determined by the number of children successfully treated without surgical intervention. Therefore, we did not have sufficient data to evaluate the effectiveness of our school screening program. Second, we did not have definite criteria for diagnosing scoliosis using Moiré topography. It is a subjective test, and this reason might contribute to the high false-positive rate. Third, although we found a significant difference in the prevalence of scoliosis between the first and current decades, our data did not allow us to determine the reason for this difference.

\section{Conclusions}

The overall prevalence of scoliosis in Nara City was lower than that reported in previous studies. In girls, the prevalence of scoliosis increased since the first decade of our study. The prevalence in boys was lower than in girls and did not change significantly over the 23 years. Our school screening test, Moiré topography, had a high falsepositive rate, which did not improve with examiner experience. Although our screening cost was less than that for surgical intervention in Japan, it was twice as high as that in Minnesota, USA. Our study has highlighted the need for further research in the area of reduction of the falsepositive rate of Moiré topography for scoliosis screening. Additionally, any future studies should focus on modifying the Moiré topography for use as an accurate screening tool through skeletal maturity and extend the assessment to include benefits, cost savings, risks, and indirect costs to the children and to society in order to determine a cost-benefit estimate.

\section{Conflict of Interest}

No potential conflict of interest relevant to this article was reported.

\section{References}

1. Pehrsson K, Larsson S, Oden A, Nachemson A. Long-term follow-up of patients with untreated scoliosis: a study of mortality, causes of death, and symptoms. Spine (Phila Pa 1976) 1992;17:1091-6.

2. Katz DE, Herring JA, Browne RH, Kelly DM, Birch JG. Brace wear control of curve progression in adolescent idiopathic scoliosis. J Bone Joint Surg Am 2010;92:1343-52.

3. Richards BS, Vitale MG. Screening for idiopathic scoliosis in adolescents: an information statement. J Bone Joint Surg Am 2008;90:195-8.

4. Karachalios T, Roidis N, Papagelopoulos PJ, Karachalios GG. The efficacy of school screening for scoliosis. Orthopedics 2000;23:386-91.

5. Adobor RD, Riise RB, Sorensen R, et al. Scoliosis detection, patient characteristics, referral patterns and treatment in the absence of a screening program in Norway. Scoliosis 2012;7:18.

6. Yawn BP, Yawn RA, Hodge D, et al. A populationbased study of school scoliosis screening. JAMA 1999;282:1427-32.

7. Wong HK, Hui JH, Rajan U, Chia HP. Idiopathic scoliosis in Singapore schoolchildren: a prevalence study 15 years into the screening program. Spine (Phila Pa 1976) 2005;30:1188-96.

8. Adair IV, Van Wijk MC, Armstrong GW. Moire topography in scoliosis screening. Clin Orthop Relat Res 1977;(129):165-71.

9. Daruwalla JS, Balasubramaniam P. Moire topography in scoliosis: its accuracy in detecting the site and size of the curve. J Bone Joint Surg Br 1985;67:211-3.

10. Laulund T, Sojbjerg JO, Horlyck E. Moire topography in school screening for structural scoliosis. Acta Orthop Scand 1982;53:765-8.

11. Zhang GP, Li ZR, Wei XR, Cao YL, Cui QL. Screening for scoliosis among school children in Beijing. Chin Med J (Engl) 1988;101:151-4.

12. Ohtsuka Y, Yamagata M, Arai S, Kitahara H, Minami S. School screening for scoliosis by the Chiba University Medical School screening program. Results of 1.24 million students over an 8-year period. Spine (Phila Pa 1976) 1988;13:1251-7.

13. Stirling AJ, Howel D, Millner PA, Sadiq S, Sharples D, Dickson RA. Late-onset idiopathic scoliosis in children six to fourteen years old: a cross-sectional prev- 
alence study. J Bone Joint Surg Am 1996;78:1330-6.

14. Ascani E, Bartolozzi P, Logroscino CA, et al. Natural history of untreated idiopathic scoliosis after skeletal maturity. Spine (Phila Pa 1976) 1986;11:784-9.

15. Howell FR, Mahood JK, Dickson RA. Growth beyond skeletal maturity. Spine (Phila Pa 1976) 1992;17:43740.

16. Little DG, Song KM, Katz D, Herring JA. Relationship of peak height velocity to other maturity indicators in idiopathic scoliosis in girls. J Bone Joint Surg Am 2000;82:685-93.
17. Orito S, Kuroda T, Onoe Y, Sato Y, Ohta H. Age-related distribution of bone and skeletal parameters in 1,322 Japanese young women. J Bone Miner Metab 2009;27:698-704.

18. Fong DY, Lee CF, Cheung KM, et al. A meta-analysis of the clinical effectiveness of school scoliosis screening. Spine (Phila Pa 1976) 2010;35:1061-71.

19. Yawn BP, Yawn RA. The estimated cost of school scoliosis screening. Spine (Phila Pa 1976) 2000;25:238791. 